\title{
Mengimplementasikan Prinsip Pengembalaan Menurut 1 Petrus 5:1-5
}

\author{
Ceria $^{1 *}$, Robert Octavianus ${ }^{2}$, Sudiadi Siregar ${ }^{3}$, Almart Yosfri Simamora ${ }^{4}$ \\ Sekolah Tinggi Teologi Real, Batam \\ *correspondence email: ceria2988@gmail.com
}

\begin{abstract}
Every pastor must have principles in carrying out his ministry as the main guide in acting and thinking in carrying out his ministry duties. The pattern of life and character of a pastor in carrying out pastoral ministry greatly affects the life of the congregation, therefore it is necessary to understand how the principles of pastoral care and also the pattern in their application in the ministry itself The use of 1 Peter 5-1:5 is not without reason, this is because there are pastors who are not fully aware of the duties and responsibilities associated with the position as pastor of the congregation, and this is what encourages the author to compile and explore what the Bible says about the principles of shepherding in 1 Peter 5:1-5 and how these principles can be applied in service today. Research method, the author uses a qualitative research method approach to descriptive analysis, with an exposition approach to the text of 1 Peter 5:1-5, namely: first, the shepherd has the responsibility to feed his sheep, serve not because forced and looking for personal gain, and placing oneself as a servant, namely serving the congregation and having a willingness to serve unconditionally and being willing to sacrifice in carrying out services for the benefit of the congregation.
\end{abstract}

Keywords: 1 Peter 5; church ministry; pastor; shepherding

\begin{abstract}
Abstrak
Setiap gembala harus memiliki prinsip pelayanan sebagai pedoman bertindak dan berpikir dalam melakukan tugas pelayanannya. Pola hidup dan karakter seorang gembala dalam menjalankan pelayanan Pastoral mempengaruhi kehidupan jemaat. Oleh sebab itu sangat diperlukan pemahaman tentang prinsip-prinsip pengembalaan. Penggunaan 1 Petrus 5-1:5 bukanlah tanpa alasan, penulis untuk menyusun dan menggali apa kata Alkitab tentang bagaimana prinsip-prinsip penggembalaan dalam surat 1 Petrus 5:1-5, dan bagaimana prinsip tersebut dapat diterapkan dalam pelayanan saat ini. Metode penelitian, penulis menggunakan pendekatan metode penelitian kualitatif analisis deskriptif, dengan pendekatan eksposisi pada teks 1 Petrus 5:1-5. Yakni, gembala menyadari tanggung jawabnya dalam memberi makan dombanya serta melayani bukan karna terpaksa dan mau menempatkan diri sebagai seorang hamba yaitu melayani jemaat serta memiliki kerelaan hati untuk mengabdi tanpa pamrih dan rela berkorban dalam melakukan pelayanan-pelayanan demi kepentingan jemaatnya.
\end{abstract}

Keyword: 1 Petrus 5; gembala; pelayanan gereja; penggembalaan

\section{PENDAHULUAN}

Dalam pelayanan pengembalaan, seorang gembala bukan sekedar jabatan yang melekat dalam kepribadian seseorang yang diangkat oleh suatu organisasi, melainkan juga panggilan Allah yang memiliki tanggung jawab besar baik itu secara moril maupun secara spiritual karena Allah sendirilah yang menetapkannya. Oleh sebab itu seorang gembala berkewajiban untuk menyadari akan posisinya tersebut sehingga dalam pelayanannya ia bukan hanya mengetahui tanggung jawabnya namun juga dapat menger- 
jakannya dengan benar. Perlu adanya hikmat dan pimpinan dari Allah dalam mengerjakan tugas tersebut. Dalam era globalisasi abad ini ada banyak tantangan-tantangan dalam penggembalaan digereja. Dan hal ini menjadi semakin kompleks dan saling berkaitan dengan faktor lainnya bagi gembala itu sendiri, maupun pelayanan lain yaitu penginjil, diaken maupun hamba Tuhan lainnya. ${ }^{1}$

Sepanjang sejarah gereja, ada banyak gembala yang berhasil mengembangkan jemaatnya, dan banyak juga yang gagal, hal ini dikarenakan gembala tidak memiliki pedoman akan prinsip-prinsip yang benar dalam melaksanakan tugas pelayanannya. Menurut Halim dalam Daniel Wenggi gereja membutuhkan kepemimpinan yang alkitabiah, sungguh-sungguh melayani untuk kepentingan dan kemajuan jemaat, berorientasi kepada visi serta mampu menghadapi segala tantangan dan hambatan dalam pelayanan pastoral. ${ }^{2}$ Artinya, setiap gembala harus memiliki prinsip dalam melakukan pelayanannya sebagai pedoman utama dalam bertindak dan berpikir dalam melakukan tugas pelayanannya.

Gembala semestinya wajib menjadi gembala bagi jemaat atau "dombanya" istilah ini sendiri dihubungkan dengan diri Yesus Kristus dan karya-Nya sebagai "Gembala Sejati", atau "Gembala yang Baik". Ungkapan ini mengacu kepada pelayanan Yesus yang tanpa pamrih, bersedia memberi pertolongan dan pengasuhan terhadap para pengikut-Nya, bahkan rela menyerahkan nyawa-Nya. ${ }^{3}$ Gembala merupakan manusia biasa memiliki kecendrungan untuk berdosa, karena itu ketika dipanggil menjadi pelayan-Nya berarti ia tidak lagi berpikir secara dunia dan mementingkan dirinya dalam segala hal yang dirinya butuhkan secara keinginan duniawi, dan hidupnya hanya untuk menjalankan pekerjaan Tuhan, bergaul dengan Tuhan, berpikir seperti Tuhan dan melakukan segala sesuatu seperti untuk Tuhan.

Pola hidup dan karakter seorang gembala dalam menjalankan pelayanan Pastoral sangat mempengaruhi kehidupan jemaat, dan seorang gembala juga merupakan pengatur yang berdiri dihadapan untuk memimpin, mengatur, mengarahkan dengan praktik. ${ }^{4}$ Artinya keteladaan ini menjadi sarana Pendidikan yang efektif dalam kehidupan rohani jemaat. oleh sebab itu sangat di perlukan pemahaman tentang bagaimana prinsip-prinsip pengembalaan dan juga pola dalam penerapanya di dalam pelayanan itu sendiri.

Menurut Yosafat B dalam buku Harianto GP, beberapa masalah yang terjadi dalam pelayanan adalah hamba Tuhan yang masih terikat dengan kemewahan yang di tawarkan oleh dunia sehingga mereka menggunakan demi memuaskan keinginan mereka sendiri, dan bahkan inventaris gereja dianggap sebagai milik pribadi. Kasus lain adalah, adanya ganguan psikologis dalam diri sorang gembala yang berwujud kesombongan, perasaan rendah diri yang akan mereka tutupi dengan penampilan berlebihan seperti selebriti, serta kesaksian yang sepektakuler yaitu makan bersama para pejabat

${ }^{1}$ Eko Prasetyo, "Prinsip-Prinsip Pengembalaan (Yohanes 21:15-17),” Real Didache 1, no. 1 (2016): 123 .

${ }^{2}$ Daniel Wenggi and Sutikto Sutikto, "Prinsip Penggembalaan Menurut 1 Timotius 4: 1-16: Kajian Reflektif Untuk Penerapan Di GPdI Wilayah Waropen Barat, Papua," EPIGRAPHE: Jurnal Teologi dan Pelayanan Kristiani 4, no. 1 (2020): 31-43.

${ }^{3}$ Harianto GP, Teologi Pastoral (Yogyakarta: ANDI Offset, 2020). 80

${ }^{4}$ Derek J Tidball, Teologi Pengembalaan (Malang: Yayasan Penerbit Gandum Mas, 2002), 12. 
dan orang-orang penting lainnya, masalah seks yang sering terjadi karena pemimpin pastoral jatuh dalam dosa perzinahan, dan juga gembala lebih senior yang kadang bertindak diskriminatif dan menindas pendeta yang lebih muda hanya kaena alasan yang bersifat prinsipil. ${ }^{5}$ Penggunaan 1 Petrus 5-1:5 bukanlah tanpa alasan, hal ini di karenakan adanya gembala yang belum sepenuhnya menyadari akan tugas dan tanggung jawab berkaitan dengan jabatan sebagai gembala warga jemaat, dan hal ini lah yang mendorong penulis untuk menyusun dan menggali apa kata Alkitab tentang bagaimana prinsip-prinsip penggembalaan dalam surat 1 Petrus 5:1-5 dan bagaimana prinsip tersebut dapat diterapkan dalam pelayanan saat ini. Nasihat Petrus dalam teks tersebut ditujukan kepada penetua jemaat, juga dapat diterapkan bagi gembala sidang dalam menjalankan pelayanannya.

\section{METODE}

Metode penelitian, penulis menggunakan pendekatan metode penelitian kualitatif analisis deskriptif, dengan pendekatan eksposisi pada teks 1 Petrus 5:1-5 dan penulis melakukan penelitian pustaka terhadap berbagai sumber yang membahas tentang prinsip pengembalaan sehingga dapat diimplementasikan dalam kehidupan pelayanan pastoral saat ini. Demikian juga Sugiono mengungkapkan bahwa penelitian deskriptif kualitatif adalah penelitian yang berusaha untuk menuturkan pemecahan masalah yang ada berdasar data-data mengikuti teknik pengolahan dan analisis data. ${ }^{6}$

\section{PEMBAHASAN}

\section{Prinsip-prinsip Pengembalaan Menurut 1 Petrus 5:1-5}

Dalam 1 Petrus 5:1-5 jika digali secara eksposisi, maka penulis memak-nai beberapa prinsip pengembalaan yang dapat dijadikan pedoman bagi gembala saat ini.

Ayat kesatu, ada dua hal yang harus dipelajari sebelumnya bagi para gembala maupun hamba Tuhan, Pertama, "Aku Menasihatkan"; kata tersebut dalam terjemahan New American Standard Bible (NASB) adalah "Therefore, I exhort” yang berarti "Karena itu, aku meendesak atau menasehati", dan hal ini memiliki keterkaitan dengan teks sebelumnya tentang penghakiman Allah yang ada dalam gereja. ${ }^{7}$ Penatua sebagai bagian dari kelompok tertinggi, merupakan golongan yang paling terbuka terhadap penghakiman Allah dalam gereja, dan dikerenakan adanya penghakiman tersebut maka pengembalaan yang setia dari para penetua sangat diperlukan oleh orang-orang Kristen saaat ini.

Kedua, "para penatua". Ronal G. Sirait mengatakan, menurut Calvin penatua merupakan kata penghormatan, bukan dikarenakan usia yang lebih tua, namun seseorang yang telah di pilih kerena memiliki kebijaksanaan, kesungguhan, dan pengalaman. ${ }^{8}$ Contohnya Timotius yang dipilih untuk ada dalam kedudukan tersebut sekalipun dari segi usia masih sangat muda namun memiliki kriteria yang cocok sebagai seorang penatua. Sebagai seorang penatua, kewajiban yang harus dilakukan ialah mengajar

\footnotetext{
${ }^{5}$ Harianto GP, Teologi Pastoral. 82-83

${ }^{6}$ Sugiono, Memahami Penelitian Kualitatif (Bandung: CV Alfabeta, 2016). 16.

7 “New American Standard Bible.”Diakses 22 April 2021.

${ }^{8}$ Ronal G Sirait, Pelayanan Pastoral Pemimpin Muda Dalam Kitab Timotius (Malang: Ahlimedia Press, 2020).
} 
orang lain dengan teliti dan berhati-hati tentang kewajiban diri sendri dan juga kewajiban orang lain. Sedangkan di ayat kedua, hali ini berbicara tentang prinsip-prinsip yang bukan hanya berlaku pada penatua, melainkan juga semua pelayan Kristen, untuk membentengi dari sifat buruk yang banyak di temukan, yaitu kemalasan, keinginan akan keuntungan, dan nafsu kekuasaan.

\section{Eksposisi 1 Petrus 5:1-5}

\section{Gembalakanlah}

Jika dilihat dari sejarah penulisan kitab 1 Petrus 5:1-5 tentang kepada siapa Petrus menulis surat ini, maka dapat diindikasikan surat ini dikirim kepada orang-orang Kristen yang sedang menderita dan dianiaya, akan tetapi diminta untuk melayani. Kata "Gembalakan dalam King James Version adalah "feed", yaitu "berilah makan", dan dalam terjemahan lain Revised Standard Version, kata itu berarti "peliharalah". Kata peliharalah tersebut merujuk kepada semua hal tentang kewajiban seorang gembala, yaitu membimbing, menjaga, menggiring kedalam kandang serta memberi makanan. Memang, istilah "memberi makan" bukanlah satu-satunya tugas gembala, tetapi jelas merupakan salah satu tugas terpenting gembala yang juga ditulis dalam Mazmur 23:2 dan Yehezkiel 34:14, di mana gembala membimbing dombanya ke pada air yang tenang dan rumput yang subur sebagai mkanannya. ${ }^{9}$

Dalam melayani jemaat Tuhan sikap yang harus dimiliki oleh gembala adalah melayani dengan sukarela, di mana hal pertama kata gembala bukan hanya berbicara tentang posisi atau kedudukan tertinggi di dalam gereja. Sebab, jika gembala hanya ditinjau dari sudut jabatan, maka sikap yang timbul di dalam pelayanan lebih cenderung kepada sikap memimpin tanpa kerelaan hati dan sukarela. ${ }^{10}$ Memberi makanan bagi domba-dombanya adalah hal yang berkaitan dengan memimpin orang-orang untuk menerima, memercayai, serta mengasihi Firman Tuhan. Hal tersebut merupakan fodasi utama kehidupan orang percaya, sehingga mampu memberikan perlindungan terhadap ajaran sesat, memberi nasihat, menuntun, menghibur, dan memberikan kekuatan sehingga jemaat mampu menghadapi kesukaran dan perjuangan hidup dan secara berkesinambungan memberi pimpinan dalam nengarahkan langkah hidup dalam kebenaran sesuai kehendak Tuhan. ${ }^{11}$

\section{Memelihara}

Kata berikutnya adalah "memelihara", atau mengembalakan yang juga berarti berjagajaga, di mana gembala harus menyadari jiwa-jiwa yang telah ditebus melalui kematian Kristus merupakan hal yang sangat berharga di mata Allah. Karena itulah jiwa tersebut juga berharga bagi gembala maupun hamba Tuhan lainnya. Gembala harus berjaga-jaga bagi jiwa-jiwa, yang karenanya darah yang berharga dicurahkan adalah sangat berharga di mata Allah. Hal yang dikhususkan dalam hal berjaga-jaga tersebut dijelaskan dalam Kisah Para Rasul 20:17, 28-31. Dari teks tersebut menunjukkan bahwa Tuhan memperoleh gereja atau jemaat dengan darah-Nya sendiri. Dan menujukan bahwa penatua

\footnotetext{
9 "Studi Kamus," Alkitab Sabda.

${ }^{10}$ Simon J Kistemaker, New Testament Commentary: Exposition of The Epistles of Peter and of The Epistle of Jude (Michigan: Baker Book House, 1987),191.

${ }^{11}$ Joko Santoso, "Pelayanan Hamba Tuhan Dalam Tugas Penggembalaan Jemaat," Sanctum Domine: Jurnal Teologi 9, no. 1 (2020): 17.
} 
wajib menjaga jemaat Allah dan menjaga mereka terhadap serigala "nabi-nabi palsu". Dalam Yehezkiel 34:1-6, 11-12, 16 terlihat jelas tentang mengapa domba-domba tersebut harus digembalakan; domba tersebut akan berserak dan mereka akan menjadi makanan bagi segala binatang di hutan, bahkan menjadi tersesat.

Hamba Tuhan memiliki tanggung jawab untuk mengawasi dan memelihara kebutuhan rohani jemaat, memberitakan ajaran yang sehat, serta menjadi teladan dalam kesucian dan pengajaran yang benar. Sehingga semua orang percaya tetap hidup dalam kasih karunia Allah. ${ }^{12}$

\section{Jangan dengan Paksa}

Dalam ayat yang kedua dikatakan, "Jangan dengan paksa, tetapi dengan sukarela sesuai dengan kehendak Allah.” Bandingkan ayat ini dengan Yohanes 10:11-13, di mana gembala yang baik akan memberikan nyawanya bagi domba-dombanya, sedangkan seorang upahan yang bukan gembala, dan bukan pemilik domba tersebut, ketika melihat serigala datang, ia meninggalkandomba-domba itu lalu lari. Sehingga, serigala tersebut mencerai-beraikan domba-domba itu. Sirait mengutip Calvin, mengatakan bahwa seorang gembala tidak boleh memperhatikan kawanan domba Tuhan hanya sejauh mereka didesak atau dipaksa, karena mereka yang berusaha melakukan dengan cara dipaksa, mereka akan lalai dengan tanggung jawab mreka tersebut. ${ }^{13}$ Akan tetapi jika seseorang gembala sungguh-sungguh melakukan dengan sukarela, mereka akan berbakti dan bertanggung jawab pada pekerjaan mereka. Dalam konteks saat ini, beberapa hamba Tuhan terpanggil khusus untuk menjadi gembala, namun ada juga para pemimpin jemaat yang terpaksa menjadi pemimpin karena meneruskan posisi orang tua mereka sebelumnya yang adalah gembala sehingga dalam hal melayani seseorang tersebut tidak memiliki panggilan yang kuat didalam dirinya untuk menjadi seorang hamba Tuhan yang setia. ${ }^{14}$

\section{Jangan Mencari Keuntungan}

Berikutnya adalah ungkapan, “...dan jangan karena mau mencari keuntungan, tetapi dengan pengabdian diri." Dalam terjemahan KJV klausa tersebut berbunyi: "not for filthy lucre", yang berarti "bukan untuk uang kotor". Terjemahan lain NIV "not greedy for money", yang berarti "tidak tamak akan uang". Hal ini memiliki hubungan dengan dengan 1 Timotius 3:8, di mana seorang diaken disebut agar "janganlah serakah", yang dalam terjemahan KJV "not greedy of filthy", artinya "tidak tamak dengan uang kotor". Alan M. Stibbs dalam Hanok Tuhumury menyatakan, pekerjaan yang mereka lakukan haruslah dengan motivasi yang benar, bukan untuk keuntungan diri sendiri. ${ }^{15}$ Hal ini juga diungkapkan oleh Calvin karena siapa pun yang memiliki tujuan hanya untuk dirinya sendiri, bukanlah seorang pelayan Kristus, tetapi soerang budak bagi perutnya sendiri. ${ }^{16}$

Penting sekali sikap sukarela ini dimiliki oleh gembala agar melayani tanpa beban dan tanpa motivasi yang kurang baik. Sebab, jika melayani sebagai gembala tidak suka-

\footnotetext{
12 “Artikel Penuntun - KARUNIA-KARUNIA PELAYANAN GEREJA," https://alkitab.sabda.org/ diakses, 24 juni 2021.

${ }^{13}$ Sirait, Pelayanan Pastoral Pemimpin Muda Dalam Kitab Timotius.hal. 28.

${ }^{14}$ Hanok Tuhumury, "PELAYANAN PASTORAL KONSELING BERDASARKAN 1 PETRUS

5 : 1 - 11," Missio Ecclesiae 7, no. 1 (2018): 90.

15 Ibid.

${ }^{16}$ Sirait, Pelayanan Pastoral Pemimpin Muda Dalam Kitab Timotius.hal 29.
} 
rela, maka cenderung pelayanan itu akan mengacu kepada kepentingan pribadi, sehingga jika pelayanan itu tidak memberikan keuntungan pribadi, maka pelayanan itu akan diabaikan dan dengan mudah akan mencari pelayanan yang lain dengan tujuan untuk mencari kesenangan serta keuntungan pribadi dalam segala hal.

\section{Janganlah Kamu Berbuat Seolah-olah Kamu mau Memerintah}

Nas lain berikutnya adalah, "Janganlah kamu berbuat seolah-olah kamu mau memerintah atas mereka yang dipercayakan kepadamu, tetapi hendaklah kamu menjadi teladan bagi kawanan domba itu." Bandingkan dengan Matius 20:26-28, dikatakan "Barangsiapa ingin menjadi yang terbesar hendaklah ia menjadi pelayanmu, dan barangsiapa yang ingin menjadi yang terkemuka diantara kamu hendaklah ia menjadi hambamu..." Ditegaskan dalam ayat berikutnya, "Jka Anak Manusia datang bukan untuk dilayani melainkan utuk melayani dan memberikan nyawa-Nya menjadi tebusan bagi banyak orang." Sirait kembali mengutip Calvin menyatakan, jika sifat buruk berikutnya adalah nafsu untuk menggunakan kekuasaan dan kedudukan sehingga melahirkan sifat kesombongan pada diri seorang gembala. ${ }^{17}$ Gembala jemaat harus memperlakukan anggota jemaatnya sebagai kawan sekerja Allah, sebagai pusaka Allah, bukan sebagai milik untuk diperlakukan sekehendaknya saja. Umat Allah harus diperlakukan dengan kasih, kesabaran dan kelemah lembutan.

\section{Mengimplementasi dalam Pelayanan}

Semua orang yang dinasihati dalam konteks nas di atas adalah para majelis, pendeta, dan semua pelayan jemaat; sementara yang memberikan nasihat adalah rasul Petrus yang ingin mengajari orang lain agar benar-benar bertanggung jawab atas tugas dan panggilan mereka. Seorang pelayan Tuhan adalah seseorang yang benar-benar melayani Tuhan, apa yang dilakukannya berfokus pada kehendak Tuhan, sekalipun banyak rintangan dan halangan yang di alaminya. Melayani Tuhan bukan hanya berdasarkan perkataan saja, namun disertai dengan perbuatan yang nyata dalam kehidupannya sepabai pelaku Firman.

Hal utama yang harus dilakukan gereja dewasa ini adalah bagaimana penerapan prinsip-prinsip penggembalaan tersebut di dalam pelayanan sehari-hari serta menjadikan prinsip tersebut sebagai dasar acuan untuk bertindak dan evaluasi bagi para pemimpin gereja atau gembala. Dalam penerapan prinsip penggembalaan sering kali terjebak dalam hal yang praktis dan melupakan mengenai doktrin alkitabiah. Pertama, dalam hal mengembalakan tentu yang harus diperhatikan adalah cara menyampaikan firman Allah yang murni, memimpin mereka sesuai dengan ketetapan Firman Allah, serta mengawasi dan menasihati jemaat untuk menjaga kawanan domba yang dipercayakan ke dalam tangan mereka. Sebelum seorang pemimpin jemaat menyampaikan Firman Allah, maka pengetahuan mengenai Firman Allah ini juga harus benar. Oleh karena itu, perlu ada satu standar baku mengenai kualitas penyampaian Firman Allah. Hal ini berkaitan erat dengan prinsip pengembalaan di poin yang pertama, yakni "Gembalakanlah dan memelihara", di mana gembala betanggung jawab dalam memimpin jemaat untuk mengenal dan memahami kebenaran prinsip Firman Tuhan. ${ }^{18}$ Oleh sebab itu, seorang pemimpin yang memberitakan Firman harus memiliki pengetahuan dasar

${ }^{17}$ Ibid.hal 30.

${ }^{18}$ Santoso, "Pelayanan Hamba Tuhan Dalam Tugas Penggembalaan Jemaat." 18. 
yang didapat melalui pendidikan teologi, kelas KOM, ataupun pelatihan singkat mengenai penginjilan, dan pemuridan.

Gembala sidang melaksanakan tugas sebagai pengasuh jemaat, pemimpin, pembina rohani, pendidik jemaat dalam ajaran sehat, pengawas terhadap jemaat pengajar dalam kebenaran. Hal ini dapat dimulai dengan penyampaian firman melalui khotbah, dan pendalaman Alkitab di komunitas-komunitas Kristen seperti kelompok sel yang merupakan salah satu cara terbaik untuk memulai pengawasan terhadap jemaat dan memonitor pertumbuhan dan perkembangan kerohanian jemaat. Serta melalui aplikasi media sosial dengan tujuan untuk terkoneksi dengan jemaat secara konsisten dan pengadaan pelatihan secara berkala untuk jemaat.

Kedua, menjadi teladan bagi domba-dombanya, yakni melakukan tugas bukan karena paksaan, dan tidak mencari keuntungan pribadi. Namun dengan tulus. Pemimpin jemaat harus mampu mengendalikan diri dan menghasilkan buah-buah roh yang nyata dan dapat dirasakan oleh orang orang di sekitar mereka. Para pemimpin jemaat harus bisa menjadi contoh dalam hal Kesabaran dalam membimbing jemaat untuk bertumbuh dalam Firman Tuhan dan menjadi serupa dengan Yesus. Tidak dengan paksa juga dapat diartikan bahwa pemimpin jemaat dengan sengaja melibatkan jemaat di dalam berbagai kegiatan gereja sesuai dengan kemampuan dan talentanya dan berusaha untuk mengembangkannya dengan memberikan pelatihan, konseling yang tepat kepada jemaat. Mampu mengendalikan diri dalam hal materi seperti keuangan menjadi hal penting bagi seorang pemimpin jemaat. Jangan sampai menggunakan jemaat untuk mencapai kepentingan pribadi. Menjadi penggerak dalam kegiatan sosial tanpa mengharapkan imbalan atau pujian.

Ketiga, mau menempatkan diri sebagai seorang hamba, bukan tuan atau penguasa. Hal ini berkaitan dengan poin kelima yaitu "Janganlah kamu berbuat seolah-olah kamu mau memerintah atas mereka yang dipercayakan kepadamu." Seorang pelayan Tuhan harus memiliki kerelaan hati untuk mengabdi tanpa pamrih dan rela berkorban dalam melakukan pelayanan-pelayanan demi kepentingan jemaat, memikul tanggung jawab pelayanan kasih, memelihara, menghibur, dan memenuhi kebutuhan yang nyata dalam jemaat yang digembalakan. ${ }^{19}$ Sehingga jemaat dapat merasakan dampak positif terhadap apa yang dilakukan gereja terhadap diri mereka pribadi. Kepuasan jemaat dan pelayan gereja akan berdampak nyata terhadap pertumbuhan gereja, baik secara jumlah jemaat yang baru maupun jemaat lama yang loyal. Aktivitas gereja akan semakin berkembang secara luas dan menjangkau lebih banyak orang. Ketika pemimpin bisa menempatkan dirinya sebagai pelaksana dan komandan, maka secara langsung bisa dimonitor dengan jelas setiap kegiatan di lapangan. Hal ini juga akan memberikan dorongan moral kepada para pelayan Tuhan di lapangan. Sebaliknya, jika pemimpin tidak pernah turun tangan maka menandakan bahwa pemimpin kurang peduli dengan apa yang dialami para pelayan di lapangan yang kemungkinan sebagian besar adalah pelayan suka rela.

Membangun sebuah prinsip yang benar di dalam pelayanan harus senantiasa berdasarkan kebenaran Firman Tuhan, sehingga konteks 1 Petrus 5:1-5 ini akan membangun gairah atau semangat yang selalu baru di dalam melayani Tuhan dan prinsip yang

${ }^{19}$ Ibid.hal. 21. 
dibangun dalam pelayanan adalah bergantung penuh terhadap Tuhan. Sikap dalam melayani Tuhan tentu harus bergantung penuh kepada tuntunan Roh Kudus, agar setiap pelayanan yang dijalankan senantiasa seiring dengan kerinduan Tuhan bukan kerinduan pribadi. ${ }^{20}$ Dengan bergantung penuh pada pimpinan Roh Kudus, serta bersandar penuh hanya kepada Roh Kudus akan banyak hal-hal yang dahsyat yang akan Tuhan nyatakan dalam pelayanan yang Tuhan percayakan, sebab kekuatan yang sejati di dalam pelayanan adalah mengandalkan kuasa Roh Kudus.

\section{KESIMPULAN}

Dalam tugas pengembalaan gembala harus menyadari tanggung jawab untuk memberi makan dombanya dalam hal menyampaikan firman Allah yang murni serta memimpin mereka sesuai dengan Firman Allah, serta melayani jemaat bukan karena terpaksa, sehingga gembala dapat menjadi teladan bagi domba-dombanya. Berikutnya, mau menempatkan diri sebagai seorang hamba, yaitu melayani jemaat, serta memiliki kerelaan hati untuk mengabdi tanpa pamrih, dan rela berkorban dalam melakukan pelayananpelayanan demi kepentingan jemaatnya. Sebab, penggembalaan bukan sekadar tugas jawatan gereja, melainkan panggilan Allah yang harus digenapi dan dilakukan dengan benar. Dalam pelaksanaan penggembalaan harus sesuai dengan prinsip-prinsip yang telah ditentukan Alkitab sehingga pelaksanaan tugas penggembalaan tidak hanya bersifat praktis, melainkan juga sesuai dengan doktrin Alkitab.

Implementasi model kepemimpinan gembala yang melayani berdasarkan 1 Petrus 5:1-5 seharusnya bisa diterapkan secara universal dalam pelayanan gerejawi, tanpa membuat sebuah perbedaan dan pernyataan tentang "gembala yang sukses" dengan "gembala yang belum sukses", sebab sukses atau tidaknya seorang gembala bukan diukur dari besarnya jumlah jemaat, melainkan dari sanggup atau tidaknya menerapkan prinsip-prinsip pelayanan pengembalaan berdasarkan 1 Petrus 5:1-5. Dimensi melayani dengan kerendahan hati menjadi dimensi paling dominan membentuk implementasi model kepemimpinan gembala yang melayani berdasarkan 1 Petrus 5:1-5 di kalangan gembala jemaat.

\section{REFERENSI}

Eko Prasetyo. "Prinsip-Prinsip Pengembalaan (Yohanes 21:15-17)." Real Didache 1, no. 1 (2016): 123.

Harianto GP. Teologi Pastoral. Yogyakarta: ANDI Offset, 2020.

Kistemaker, Simon J. New Testament Commentary: Exposition of The Epistles of Peter and of The Epistle of Jude. Michigan: Baker Book House, 1987.

Richards. "Expository Dictionary, Bible Words," n.d.

Santoso, Joko. "Pelayanan Hamba Tuhan Dalam Tugas Penggembalaan Jemaat." Sanctum Domine: Jurnal Teologi 9, no. 1 (2019): 1-26.

Sirait, Ronal G. Pelayanan Pastoral Pemimpin Muda Dalam Kitab Timotius. Malang: Ahlimedia Press, 2020.

Sugiono. Memahami Penelitian Kualitatif. Bandung: CV Alfabeta, 2016.

Tidball, Derek J. Teologi Pengembalaan. Malang: Yayasan Penerbit Gandum Mas, 2002.

${ }^{20}$ Richards, "Expository Dictionary, Bible Words," n.d. 
Tuhumury, Hanok. "PELAYANAN PASTORAL KONSELING BERDASARKAN 1 PETRUS 5 : 1 - 11." Missio Ecclesiae 7, no. 1 (2018): 90.

Wenggi, Daniel, and Sutikto Sutikto. "Prinsip Penggembalaan Menurut 1 Timotius 4: 116: Kajian Reflektif Untuk Penerapan Di GPdI Wilayah Waropen Barat, Papua." EPIGRAPHE: Jurnal Teologi dan Pelayanan Kristiani 4, no. 1 (2020): 31-43.

"Artikel Penuntun - KARUNIA-KARUNIA PELAYANAN GEREJA."

"New American Standard Bible."

"Studi Kamus." Alkitab Sabda. 